\title{
Sand Body Description for Upper Sangonghe Formation (Early Jurassic), Baolang Oilfield, Yanqi Basin Northwest China
}

\author{
Fahd A. Q. Al-Qaraafi and Yao Guangqing
}

\begin{abstract}
The Yanqi Basin is located NW of China, Sangonghe formation (Early Jurassic) consists mainly channels, characterized by a complex geological. The first type channel has small size and appeared in the 'well log' as bell shaped ,second type which is thin and wide appeared in the well log as box-shaped and reflects the water high energy and strong and continuous erosion. The third type of these channels is thick with coarse deposits.These channels isolated, locally connected and connected on a wide scale.The types sand body slightly curved, laterally connected and isolated. The thickness less than $10 \mathrm{~m}$, the lateral extension $320 \mathrm{~m}$ to $1650 \mathrm{~m}$. The second Sand body layer is slightly curved broadband-like with thickness of $10 \sim 20 \mathrm{~m}$, lateral extension between $1500 \mathrm{~m}$ to $2050 \mathrm{~m}$. The third type thickness is more than $20 \mathrm{~m}$, lateral extension more $4000 \mathrm{~m}$. The interlayer represented: $80 \%, 50 \%-80 \%, 30 \%-50 \%$ and less than $30 \%$.
\end{abstract}

Index Terms-Braided river, single sand body, single sand layer, sangonghe formation.

\section{INTRODUCTION}

Highlight A braided river is one which flows in two or more channels around alluvial islands. Braided channels typically occur in high gradient, bed load dominated, fluvial systems .Discharge is typically highly variable and overbank areas are not extensively vegetated. Individual channels within the braided belt are divided by alluvial island or bars. The building of these bars are important for the development and shifting of braided channels[1].Braiding begins with deposition of a submerged bar in an otherwise unbraided channel. Once the bar is established, it accretes vertically. The bar also grows in a downstream and lateral direction by deposition of further bed load material. The bar growth reduces the widths of the flanking channels, making them unstable and erosive, resulting in deepening and widening of the channels so the water level is lowered, allowing the bar to emerge as an alluvial island .The emergent island may be stabilized by vegetation, which prevents it from easy erosion. Renewed braiding of the flanking channels can lead to a braided channel marked by several islands[2].Sangonghe formation, which belongs to the shallow coarse-grained Braided River Delta [3]-[4] dissection of the genetic types and features can be divided into 17 small layer of sands $\left(\mathrm{I}_{1}{ }^{1}\right.$, $\mathrm{I}_{1}{ }^{2} \mathrm{I}_{1}{ }^{3}, \mathrm{I}_{2}{ }^{1}, \mathrm{I}_{2}{ }^{2}, \mathrm{II}_{1}{ }^{1}, \mathrm{II}_{1}{ }^{2}, \mathrm{II}_{1}{ }^{3}, \mathrm{II}_{2}{ }^{1}, \mathrm{II}_{2}{ }^{2}, \mathrm{II}_{2}{ }^{3}, \mathrm{II}_{3}{ }^{1}, \mathrm{II}_{3}{ }^{2}, \mathrm{III}_{1}{ }^{1}, \mathrm{III}_{1}{ }^{2}$, $\left.\mathrm{III}_{1}{ }^{3}, \mathrm{III}_{2}\right)[5]$.

Manuscript received November 13, 2012; revised February 17, 2013

The authors are with China University of Geosciences, Wuhan, china (e-mail: fhdf79@gmail.com, gqyao.cug.edu.cn).

\section{Geological Setting}

The Sangonghe Formation of the study area is mainly composed of gray sandstone, conglomerate, dark mudstone, and coal. The formation is deposited in braided river deltas under a humid climate, and the evidence includes: 1.The lithology is coarse on the whole. Fine conglomerate is common, and the total content of sandstone and conglomerate is high, reaching $50 \%-60 \%$, which is a typical characteristic of a braided river delta 62 . Parallel bedding and trough cross bedding are common in sandstone and conglomerate. This reflects high current velocities, also a typical characteristic of a braided river delta; 3.The roundness of grains is poor, mostly sub angular, which reflects short transportation distance and near-provenance deposition; 4.Sandstone and conglomerate are frequently interbedded with lacustrine mudstone and coal and mudstone deposited on land, showing upward-coarsening sedimentary succession, which is another characteristic of delta deposition.

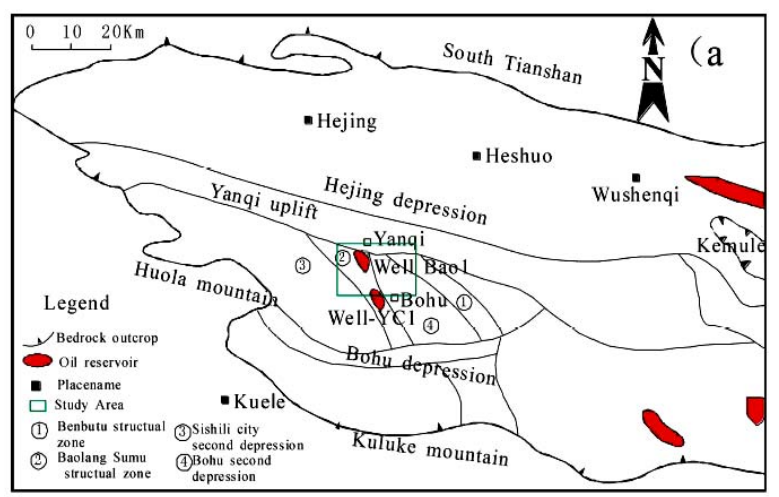

Fig. 1. location and Structure zone map in the Yanqi Basin.

\section{METHODS}

In this study, the use of well Logging Data for 124 wells as follows:

Analysis well $\operatorname{logs}$ and core to find sedimentary rock which is column properties of the study area.2.Find a relationship between the form of well logs curves (GR, SP) and the type of channels and reflected Sediment environment (for more details refer to the study Introduction by Wilson, B, W and NANS, R.H.1959)103.Finding the limits of sand body top and bottom of each well using petrel software as well as find the lateral extension of the correlation between the wells.4. Construction sand body section extends from the southeast to the northwest, which is a vertical to the direction 
of flow braided river .5.Classification sand body in terms of the degree of contact with the vertical, lateral and the degree of accumulation.6. Using petrel software program to the preparation thickness sand layers Maps.

\section{RESUlT}

\section{A. Vertical Characteristics}

Braided distributaries channel deposits to coarse granularity, multi-washed facies, heart development of beach sediment is distinguished from other channel type [6]-[7]. The core observation show the vertical retention of deposition and multi- facies alternating heart beach, overflow deposited by the river bottom. Among them, the river at the bottom of stranded deposited by the massive conglomerates, conglomerate, gravel size mixing common bell-shaped mudstone fragments and coals4, local gravels with imbricate or aligned at the bottom is strong erosion. Granularity is a probability curve or obvious two-stage. The heart of beach deposited pebbly coarse-grained sandstone and sandy conglomerate, the development of a trough-shaped, large and medium-sized wedge-shaped cross-bedding, the transition period of width, reflect with certain differentiation the sedimentary characteristics; Overflow deposited by conglomerate, medium-grained sandstone, often with thin-bedded mudstone, and development of small-scale cross-bedding1,3 wavy bedding, horizontal bedding, reflected in the low-energy flow during the flood intermittent deposition[8]-[9], the grain size showed a two-stage, and has a higher sub-diversity. Overall, the river at the bottom of stranded sedimentary composition, particle size mixed mud-based content; Overflow deposition of fine grain size, often with thin-bedded mudstone. Therefore, the heart of beach sediment as a single sand body is the most favorable reservoir sand bodies; their proportion is an important indicator for the evaluation of macroscopic heterogeneity. Differences according to the braided river sedimentary assemblages within the study area, the area of single sand body can be attributed to three kinds: 1 . Sediment grain size was fining upward, heart beach sediment development, logging in natural curve Christmas tree, to reflect the evolution of meandering river transition low-energy braided distributaries channel deposition, mainly distributed in I oil group and the small layer on top of the sand body; 2 . Sediments of the lower part of the thickness alternating change significantly thin at the top of the heart beach sediment is developed, well logs was box-shaped, reflecting the river flow is intermittent, the weakening of the upper part of the energy overflow sedimentary development, the most widely used in the study area segments; 3.Coarse granularity sediments as a whole, the heart beach deposition, especially development, logging curves groove reflect and continued the water high energy and continuous erosion and strong, is not conducive to the preservation of the overflow deposition in the study area is the most favorable reservoir single sand body.

\section{B. Single Sand Body Characteristic}

Study area of single sand body comprises three transverse section morphology: (1) Sand body channel is asymmetric lens, macrofacies with " mud pack sand " feature, lateral wide, the study area of oil group within the single sand body characteristics are very obvious, reflect the braided distributaries channel lateral accretion effect is strong, having to meandering river evolution characteristics of transition; (2) Sand body channel is thin and wide saucer, is a typical braided distributaries channel sand body styles, such as $\mathrm{III}_{2}$ layer; (3) Sand body channel is wide deep groove, such as $\mathrm{III}_{1}{ }^{1+2}$ layer. Based on the above analysis, the study area of single sand body includes three types Fig. 2.

\section{Reconstitution of Single Sand Body in Upper Sangonghe Formation}

Single sand body mode of stacking, stacked amplitude and superposition of phase in addition to $\mathrm{I}_{1}{ }^{1}, \mathrm{I}_{2}{ }^{1+2}, \mathrm{III}_{1}^{3}$ small layer sand body by isolated single sand body, other small layer sand body made of braided distributaries channel frequent migration formed single sand body interactive overlay, form with different sizes of connecting sand body. Different layer connecting sand body width / thickness ratio were $\mathrm{III}_{1}{ }^{1+2}$ small layer is greater than $4000 \mathrm{~m} / 32.18 \mathrm{~m}, \Pi_{2}{ }^{2}$ +3 is greater than $4000 \mathrm{~m} / 24.11 \mathrm{~m}, \mathrm{III}_{2}$ is $2050 \mathrm{~m} / 14.14 \mathrm{~m}$, $\mathrm{II}_{1}{ }^{3}$ is $1650 \mathrm{~m} / 9.16 \mathrm{~m}, \mathrm{II}_{3}{ }^{2}$ is $1500 \mathrm{~m} / 12 \mathrm{~m}, \mathrm{I}_{2}{ }^{3}$ is $1350 \mathrm{~m} /$ $8.16 \mathrm{~m}$. Establishment of single sand body of spatial combination relations are reservoir heterogeneity study of key, key comprises a single sand body between the horizontal continuity and vertical connectivity, lateral continuity is the single sand body lateral superposed results; Vertical connectivity is the single sand body the results, two kinds of mode of stacking different strength formed by combinations of different characteristics of reservoir connectivity. Superimposed period reflects the number of space development of the long-term, stability[10]-[11]'On the single sand body assembly includes 4 kinds of forms that splicing combination low amplitude lap combination, high amplitude lap combination and vertical combination. Thick sand body is undoubtedly by multi phase high amplitude lap combination, vertical combination to form, such as $\mathrm{III}_{1}{ }^{1+2}$ layer; Thin and wide sand body for splicing combination and low amplitude lap combination, such as a third layer 2 (Fig. 2).

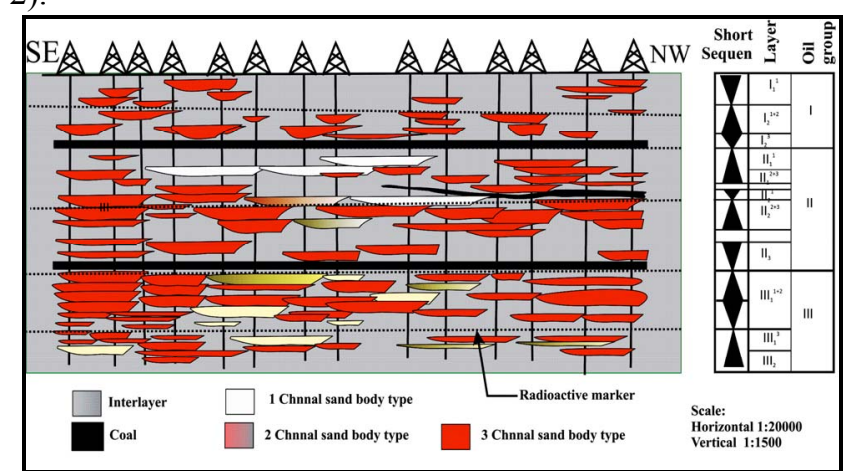

Fig. 2. Synthetic reconstitution of the reservoirs geometry in upper Sangonghe formation with base-level cycle interpretation and reservoir unit.(Location section in Fig. 4)(bigger the figure for see detail)

\section{Sand Body Units}

There are many factors affecting the shape, size and thickness of sand layers, which are fundamentally the properties of braided river, One of the most important of 
these factors for sand bodies are a function of aggradations rate, lateral channel migration and channel-belt avulsion. Through the study Bristow C.S, and J. L. Best (1993)[12], relationship between these variables and the change in the properties of sand bodes, Which classified sand to eight units, By comparing the results reached in the study area The first oil group contains the sand bodes of units $1,2,5$. The second oil group contains the sand bodes of units 4.and The third oil group contains the sand bodes of units 3.7.

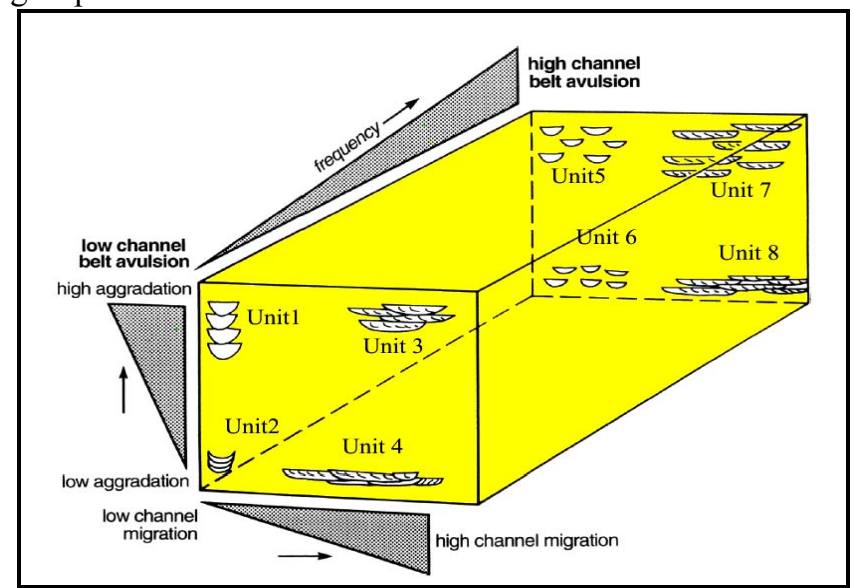

Fig. 3. Example of the sand body stacking patterns as a function of aggradations rate, lateral channel Migration and channel-belt avulsion [12]

\section{E. Construction Sand Layer Map (Isopach Map)}

The sand body plan shows that the sand body points in three kinds of types: 1 . Long and narrow strip of a sand body slightly curved, laterally connected and isolated, the thickness is less than $10 \mathrm{~m}$, reflecting a small number of distributaries channel, delta bend sedimentary development of heart beach a small number of small-scale sedimentary characteristics; 2 . Sand body slightly curved broadband-like thickness of $10 \sim 20 \mathrm{~m}$. Sand side of the body to the large thickness by the deposition barrier between the branches bend, locally connected, but the superimposed amplitude is small, and identify the style of the distributary channels and river sub-branch apparent heart beach sediment is developed; Sand takes the shape of the surface-like distribution, on the lateral connectivity of sand bodies. Overlay margin of the sand body; only indirectly reflect the number of distributary channels, heart beaches are well developed with large-scale characteristics.3. The thickness is more than $20 \mathrm{~m}$.

\section{F. Small Sand Layer in Reservoir Laminated Distribution}

Laminated is the impact of sand body connectivity degree which is one of the main factors, the small layer sand body oil gas migration has a blocking effect. Baobei Block layer is generally 2 to $6 \mathrm{~m}$, the average thickness is less than $5 \mathrm{~m}$, is mainly sedimentary mudstone interlayer. This study introduced interlayer stability coefficient, namely drilled small layer within a laminated well accounted for drilling the small layer of total well number percentage to evaluate the dissection of the lateral continuity, can be divided into 4 types of layers. (A) continuous laminated: Layer stability is greater than $80 \%$, planar distribution, good continuity, as $\mathrm{I}_{1}{ }_{1}$, $\mathrm{I}_{2}{ }^{1+2}$ small layer; (B) a continuous laminated: Layer stability ranged from $50 \%$ to $80 \%$, which seem a patchy distribution, continuity is better, as of $\mathrm{III}_{3}{ }^{1}$ small layer; (C) continuous layer: interlayer stability ranged from $30 \%$ to $50 \%$, are distributed as strips, such as type $\mathrm{II}_{2}{ }_{2}{ }^{1}, \mathrm{III}_{2}$ small layer; (D) a discontinuous layer: dissecting stability of less than $30 \%$, as type $\mathrm{II}_{2}{ }^{2+3}$, III ${ }_{1}{ }^{1+2}$ small layer. (1), (2) laminated mudstone developed horizontal bedding, wavy bedding, common fossil and bioturbation structures, for the short term transgressive form of shallow lake facies; (3), (4) laminated gray to green mudstone sedimentary structure characterize the block, common plant root fossils, the local development of thin coal seam, as reflected in a stagnant branch between the Bay and the bay between deposition Delta.
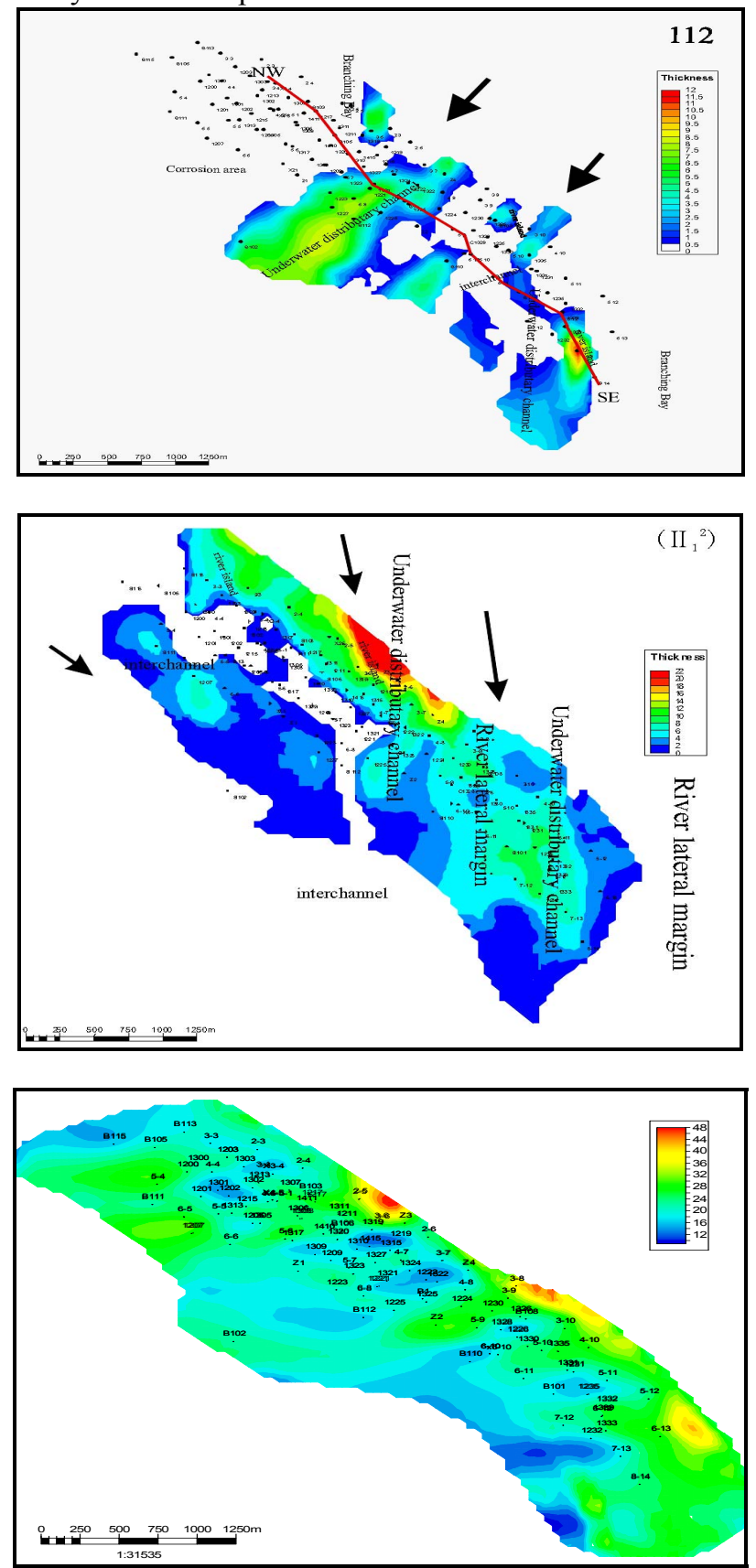

Fig. 4. Small sand layer isopach map and sedimentary facies distribution $\left(\mathrm{I}_{1}^{2}, \mathrm{II}_{1}^{2}, \mathrm{III}_{1}^{2}\right.$ from top to bottom)

\section{DISCUSSION}

Channels are related braided sloping rivers that transport sediment rough, are also characterized by a coherent aspects infrequently its decline towards the bottom and run its course, abound in the islands, which are often subjected to restructuring, and sometimes offsets, especially when severe 
flooding. In general, in many cases made up over the bottom of the channel sand dunes a small animated with the load of the bottom(layer load), and frequently channels pleated to frequent floods capable to destroy and reshape the rocky material, consisting of the islands, which abound by the results in this process also expand the Channel degree to enable them to absorb the flood waters to shorten these channels seconds (with reconfiguring the islands it) with me down the flood and thus continue in turmoil lasting during the free period of devastating floods are the channel of the accumulation of particulate matter above the formations coarse, consisting of the islands. Consisting islands coherent. This pattern is generally different from the pattern of river channels straight river channels which are usually linked to simple aspects consist of cohesive sediments minutes between them. These channels make up the environment sedimentary braided and cumulative vertically and laterally formed layers with different characteristics in terms of thickness, width, and horizontal extension (Fig. 2).Through the observed variation of the section taken lateral direction SE-NW shows that the properties of these channels may have evolved in the second oil group and the third where he became thicker layers ranging from $24.8 \mathrm{~m}$ to $17.2 \mathrm{~m}$ and the distributed constant, that the center of depositional environment different from the beach, where by tracking changes vertical shows to keep parts of the lower pattern deposition particular differs from the shore or sediment recent, that the spread of composition sediments, which is a deposition channels led to the composition glutenite huge and the accumulation of these channels valley any configuration blocks ranging permeate the gravel and sand layers and layers of mudstone are variable in size, Passed this depositional environment with three initial stages of transition and that was evident in the presentation of the channels and the different characteristics of sedimentation and the flow, which showed strength and the spread of sediment silt and discs of sandstone boulders his kind argillite often be small and overlapping, the second phase and there are horizontal layers between intermittent and sediment flood, the third phase is the reduction in the strength of flow led to the speed of sedimentation as a result of relationship reverse between strength output and particle size and the ability to transport and can be identified two parts of the bottom deposits of first clay and the other argillite. The sand blocks of three types, the first are in the form of lenses asymptomatic side (bundles of mud and sand) are characterized by change both sides of the great lithology. This type characteristic of a total of the first oil The sand distribution channel braided reflect strength developed the river at this stage, which were considered Stage Transitional. Thin layers of sand and wide and is considered a model of the braided river as an example it is a layer the $\mathrm{III}_{2}$, Sand blocks contain deep grooves in the formation of the foundation is a third group of oil.

\section{CONCLUSIONS}

Sangonghe formation consists mainly of various channels in the capacity and thickness, its extension, and contact with each other laterally and vertically. In general, the accumulation of these channels and the lateral extension and connection with each other led to the formation of objects. We were able to see through the distribution of these channels and the lateral extension and the division of layers into small composition that these layers are different from each other in terms of their characteristics. Classes $\mathrm{I}_{1}{ }^{1}$, $\mathrm{I}_{2}{ }^{1+2}, \mathrm{III}_{1}{ }^{3}$ layers are small isolated which shows the weakness in the flow channel and the weak power of flow of the river, so the channel is connected laterally. The development of the properties of these channels, such as winning in the layer $\mathrm{III}_{1}{ }^{1+2}$ have contact with the side better than its predecessors and have dimensions (W / thickness) in the range of $4000 / 32.8 \mathrm{~m}$, and $\mathrm{II}_{2}{ }^{2+3}$ is the layer dimensions (W/ thickness) in the range of $4000 / 24.1 \mathrm{~m}$, the layer $\mathrm{III}_{2}$ have dimensions (W/ thickness) in the range of $2050 \mathrm{~m} / 14.4 \mathrm{~m}$, the layer $\mathrm{II}_{1}{ }^{3}$ have dimensions $1650 \mathrm{~m} / 9.6 \mathrm{~m}$, the layer $\mathrm{II}_{3}{ }^{2}$ have dimensions $1500 \mathrm{~m} / 12 \mathrm{~m} \quad, \quad \mathrm{I}_{2}{ }^{3}$ have dimensions $1350 \mathrm{~m} / 8.6 \mathrm{~m}$. Through recombination (Fig. 3) of the layers in cross section extending from southwest to northeast we observe that the depositional characteristics of the river vary from both sides of the sand, shell, mudstone, conglomerate and coal. Through the drilled wells in the study area, we were able to follow the continuity of the sand layer and the secondary layers between them. It was found that the secondary layers which have obstructed the communication side of the sand layers take four forms. The first is laterally continuous layers of about $80 \%$ and an example of that is the piece in layers $\mathrm{I}_{1}{ }^{1}, \mathrm{I}_{2}{ }^{1+2}$.In the second type, secondary layers between sand will be between $50 \%$ and $80 \%$ and the distribution is incomplete, such as the continuity happening layer $\mathrm{III}_{1}{ }^{3}$.In the third type, the secondary layers between the sand will be between $30 \%$ and 50\%,layers are small and less lateral continuity of communication, such as the one happening in layers $\mathrm{II}_{2}, \mathrm{II}_{1}{ }^{2}$.In the fourth type, layers between the high sand may be less than $30 \%$ of such happening in the layer $\mathrm{II}_{2}{ }^{2+3}, \mathrm{III}_{1}{ }^{1+2}$. Sand body layer in the study area was divided into three main groups. The first with a thickness less than 10 meters and curved channels are extended horizontally and isolated the river reflecting the shift to a lower number of channels, and evolution of the delta. The river with sediment and shoreline of the lake sediments are a small scale in this type of sand and ranges wide. Secondary thickness ranges from 10/20 meters of a local area and branched channels and small-capacity which can recognize patterns of channels and observe the presence of sediments towards the beach. The third phase that forms a large sand thickness and contacts both sides of the well and control on the accumulation of channels and reflects the existence of distribution channels from the center towards the beach and range of this group is wide.

\section{ACKNOWLEDGEMENTS}

We are grateful to all professors in the Department of petroleum Engineering. China University of Geosciences (Wuhan) china.

\section{REFERENCES}

[1] E. W. Lane, A study of the shape of channels formed by natural streams flowing in erodible material, US Army Engineer Division, Missouri River, 1957.

[2] L. B. Leopold, M. G. Wolman, and J. P. Miller, Fluvial Processes in Geomorphology, San Francisco, Freeman and Co, 1964. 
[3] N. Hongli, "Analysis of sources of Jurassic sediments in southern sag of Yanqi basin," Henan Petroleum, vol. 4, 2005.

[4] S. H. Wu, J. Z. Kang, and C. Huang, Reservoir Modeling, Beijing Petroleum Industry Press, 1999.

[5] Y. W. Quan and Y. G. Q. Guan, "Genetic type and structure pattern of the interlayer inside thick sandbody of Baobei block in Yanqi basin," Petroleum Geology and Engineering, vol. 2, pp. 003, 2007.

[6] S. Hua and H. C. Xia. L. X. GZ, "Analysis of sequence stratigraphic framework and model of Badaowan Formation in Bohu Depression of Yanqi Basin," Lithologic Reservoirs, vol. 23, no. 1, pp. 42-46, 2011.

[7] Z. Renxiong and D. Zhizhan, "Yanqi basin Baolang low porosity and low permeability oilfield reservoir pore structure characteristics," Xinjiang Petroleum Geology,vol. 19, no. 006, pp. 485-489, 1998.

[8] O. Catuneanu, "Principles of sequence stratigraphy," Elsevier Science, vol. 58. 2006.

[9] R. S. Harris, Self-Potential Curve Shades as Indicators of Depositional Environments West Lake Verret Field, St. Martin Parish, Louisiana, Shell EPR Report 516, 1958.

[10] G. M. Wang, G. Liang, and X. M. Liu, "High Frequency Cycles and its Control Action to Lacustrine Shoal-Bar in the 4th Member of Shahejie Formation in Southern slope of Dongying Depression," Journal of earth sciences and environment, vol. 30, no. 1, pp. 44-48, 2008.

[11] H. L. Nan, "Analysis of sources of Jurassic sediments in southern sag of Yanqi basin," Henan Petroleum, vol. 4, pp. 4-5, 2005.

[12] C. Bristow and J. Best, "Braided rivers: perspectives and problems," Geological Society, London, Special Publications, vol. 75, no. 1, pp. 1-11, 1993.

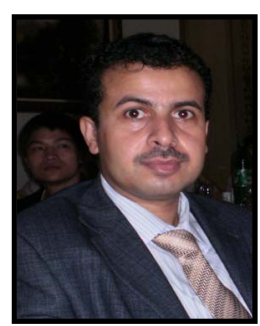

Fahd Abdo QasemAL-Qaraafi was born in Yemen, December 1st 1976. He received his B. Sac of Geology from College of Science, Department of geology, Mosel University, in Republic of Iraq (1998). His M.Sc. Degree in the field of Geology, from College of Science, Department of geology, Baghdad University, in Republic of Iraq (2002)

Now study PHD of Petroleum Geology, Faculty of Earth Resources, China University of Geosciences (Wuhan)

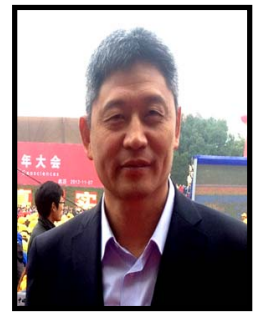

Yao Guangqing received his B. S from China University of Geosciences, 1985. His M.S. form China University of Geosciences, 1988, His PhD from China University of Geosciences, 1999.Also he was a visiting scholar in University of Kansas,U.S.2006-2007 